\title{
LA CULTURA POPULAR DE LOS ANTIGUOS NAHUAS EN LA OBRA DE FRAY BERNARDINO DE SAHAGÚN
}

\author{
Pablo Escalante Gonzalbo
}

\section{Una cultura popular}

La mayor parte de los estudios que se refieren a la religión, el arte, el lenguaje, el pensamiento y las costumbres de los antiguos nahuas suele hablar de ellos como si se tratara de un grupo homogéneo, sin diferencias internas de consideración. Dicho en otros términos, se habla, por ejemplo, de la religión de los nahuas como si hubiera un único sistema de concepciones, una sola mitología y un ritual propio de todos los nahuas. Lo mismo ocurre con otros aspectos de la cultura. Sin embargo, las fuentes coloniales que se refieren a la historia del Valle de México en vísperas de la conquista española aluden a un panorama de gran diversidad de costumbres. Incluso si se pienşa exclusivamente en la población de habla nahua, que constituía una ligera mayoría en el Valle, se encuentran diferencias que es necesario explicar y atender.

Hace tiempo que las investigaciones sobre la economía prehispánica llamaron la atención sobre una distinción básica entre pipiltin y macehual. tin; y hace tiempo se reconoce también que la distancia social entre ambos grupos era grande. ${ }^{1} \mathrm{Al}$ reflexionar sobre ese hecho, la existencia de un sistema de clases, me pregunté si no sería correcto suponer que aquella sociedad se había comportado igual que otras sociedades clasistas de la historia; es decir, si había generado manifestaciones culturales distintas según el origen de clase. Creo que la aproximación a las fuentes desde este enfoque, a partir de esta pregunta, brinda algunos resultados dignos de consideración, y no sólo aparece una diferencia en las costumbres de nobles y plebeyos: en realidad se atisba un mundo de matices y diferencias más considerables.

Creo que en términos generales puede plantearse que existió en Mesoamérica, y específicamente en el Valle de México, una oposición entre cultura popular y cultura dominante, fraguada a lo largo de siglos de

\footnotetext{
${ }^{1}$ El asunto está tratado con profundidad en Víctor Castillo: La estructura económica de la sociedad mexica, México, Universidad Nacional Autónoma de México, 1972
} 
desarrollo de sociedades clasistas pero no producida exclusivamente por esa división de clases. La cultura dominante puede caracterizarse como más compacta debido a que su construcción tuvo que ser más racional, deliberada y sistemática: obedecía a las necesidades propias del ejercicio del poder de un grupo que acaparaba funciones administrativas y rituales y era idéntico a la clase dominante. La cultura popular tuvo la riqueza y diversidad propias de numerosos oficios, diferentes fortunas y posiciones sociales, e incluso diferentes filiaciones étnicas.

Esta idea general puede ilustrarse y demostrarse gracias a la obra de Sahagún, y sería imposible hacerlo sin ella. La referencia a otras fuentes permite afianzar algunas hipótesis, pero sólo la riqueza del material reunido por Sahagún es suficiente para un estudio de la diversidad cultural indígena y en particular de la cultura popular en el contexto de la antigua sociedad nahua.

Hace algunos algunos años, en el seminario de Santa Fe, Edward Calnek llamaba la atención sobre el carácter parcial de la obra de Sahagún. En aquella ocasión Calnek mencionaba que dicha obra "refleja la perspectiva social de una pequeña minoría de la población indígena", ${ }^{2}$ y llamaba la atención sobre el hecho de que "la situación de las masas urbanas de Tenochtitlan y Tlatelolco emerge solamente de referencias dispersas y fragmentarias". ${ }^{3}$ No pretendo aquí contradecir a Calnek; estoy básicamente de acuerdo con él. Desearía apuntar que esas "referencias dispersas y fragmentarias", a pesar de serlo, permiten una aproximación suficiente para percibir los contrastes entre una cultura dominante y una cultura popular. Además, hay que aceptarlo, no hay una fuente mejor; de manera que tenemos que trabajarla con la mayor intensidad posible.

Quisiera dar algunos ejemplos de esta oposición entre cultura dominante y cultura popular y presentar la información que el corpus sahaguntino puede ofrecer al respecto. Para ello haré una recapitulación de temas que he trabajado y ordenaré su presentación por grupos sociales: primero mercaderes, luego marginados y delincuentes y por último el pueblo llano.

\section{Los mercaderes como pueblo}

Estamos bastante acostumbrados a identificar a los mercaderes como un

\footnotetext{
${ }^{2}$ Edward E, Calnek: "The Sahagun texts as a source of sociological information", en Munro Edmonson ed., Sixteenth Century Mexico, Albuquerque, University of New Mexico Press, 1974, p. 189 .

${ }^{3}$ Ibid., p. 190
} 
grupo cercano a la nobleza. El eco de sus espléndidas fiestas llega hasta las páginas de varias fuentes, de tal modo que su opulencia y el ademán de derroche que significa comprar esclavos para sacrificio define la imagen que tenemos de ellos su eventual cercanía a palacio para la toma de decisiones relacionadas con la guerra completa el cuadro de un grupo privilegiado. Sin embargo, las cosas no parecen haber sido exactamente así “ Las diferentes etnias dedicadas al intercambio tenían sus linajes dirigentes, así que algunas familias dentro del grupo concentraban mayor riqueza y lo expresaban en determinadas ocasiones por medio del dispendio. La riqueza no era estable pero cuando había recursos se gastaban. Como apunta Sahagún, se hacían grandes fiestas porque los mercaderes traían caudal. ${ }^{5}$

En la vida cotidiana, fuera de las casas de los jefes étnicos, los mercaderes son afanosos trabajadores que sufren penalidades y escasez como cualquiera. La mayor parte del tiempo los mercaderes se encuentran en ruta, y esto quiere decir que se encuentran expuestos a numerosos contratiempos: se fatigan hasta caer derrumbados en el suelo, pasan varias noches a la intemperie esperando a que disminuya el torrente de un río para poder vadearlo, mueren despeñados en un barranco, el río les arrebata las cargas, sufren severos cambios de temperatura, desde la nevada en un collado del Popocatépetl hasta los calores llenos de mosquitos de las selvas de Chiapas; se llenan de polvo y se lastiman la frente con el mecapal, duermen incómodamente junto a la puerta de una casa donde les dan posada, se les lastiman los pies con las espinas del camino, son prendidos y ajusticiados por los soldados de provincias enemigas que vigilan las fronteras, son devorados por las fieras, etcétera.

Toda esta información, salpicada aquí y allá en el Códice Florentino, proporciona una imagen próxima y cotidiana de los mercaderes, e incluso existen pasajes que nos permiten esbozar los perfiles de sus culturas étnicas: costumbres muy peculiares como la velada de las flores de los acxotecah, un género de tradición oral propio como las historias de travesía, conocimientos propios del oficio como la cartografía; además de un dios tutelar propio, símbolos, adoratorios y atuendo.

\footnotetext{
${ }^{4}$ Por no saturar con notas este trabajo de balance, remito al lector a los textos donde cada problema fue abor dado. El material sobre mercaderes, salvo nota que indique otra cosa, está comentado en Pablo Escalante, "Caminos y caminantes en Mesoamérica", en Encuentros y desencuentros en las artes. Memoria del XIV Coloquio Internacional del Instituto de Investigaciones Estéticas, México, Universidad Nacional Autónoma de México, en prensa.

${ }^{5}$ La expresión literal de Sahagún, Fray Bernardino de Sahagún: Historia general de las cosas de la Nueva España, México, Porrúa, 1979, p 46-47.
} 


\section{Marginados y criminales}

En otras ocasiones me he referido a la población marginal del Valle de México, ${ }^{6}$ ahora lo hago por última vez en vísperas de la aparición de un trabajo sobre el tema.

Cundió en numerosos estudios sobre el México prehispánico la idea de una sociedad autoritaria y rígida, representada por un poder vertical absoluto. Junto a esta idea venía la de que la población estaba perfectamente organizada en grupos cerrados, sin individuos sueltos, por así decirlo. Nuestro conocimiento de que en la ciudad de Tenochtitlan había un toque de queda nocturno fortalecía la noción de una sociedad urbana ordenada y bajo control.

El estudio detenido de los manuscritos de Sahagún y sus informantes pone en evidencia un panorama diferente. Ciertamente no puede negarse que había en palacio una pretensión de control absoluto sobre la población pero la capacidad de control y las posibilidades reales de imposición eran limitadas. Además, es claro que la población no se reducía a las comunidades organizadas en barrios y mucho menos a escuadrones vigesimales como absurdamente se ha sugerido. ${ }^{7}$ Tenemos muchos individuos que se ganan la vida azarosamente, cuyo destino es incierto y que viven al margen del orden comunitario.

Las continuas guerras, el crecimiento de la población y de los espacios urbanos, y el incremento en la circulación de productos en el Valle de México durante los últimos años de la época prehispánica, fueron fenómenos que dieron lugar a formas de supervivencia -quizá inéditas en Mesoamérica-individuales y frecuentemente delictivas. Estos individuos dotaron de un matiz peculiar a la cultura popular prehispánica del Valle de México -he comentado que constituyen la picaresca de la región-, y su importancia numérica parece haber sido grande.

Saltimbanquis, titiriteros, malabaristas y acróbatas buscaban un modo de vida con su ingenio y su destreza, y a veces se encontraban en palacio, junto a enanos y tullidos. Los magos no siempre pertenecían a una comunidad; también los hallamos deambulando por el mundo como iluminados, como hombres de conocimiento, a veces reclamados y a veces

\footnotetext{
${ }^{6}$ Pablo Escalante, "Insultos y saludos de los antiguos nahuas. Folklore e historia social", en Anales del Instituto de Investigaciones Estéticas, núm. 61 (México, 1990). Pablo Escalante, "Caminos y caminantes... ", op cit.

${ }^{7}$ Comento el problema de los escuadrones vigesimales en Pablo Escalante, "La polémica en torno a la organización de las comunidades de productores", Nueza Antropología, núm. 38 (México, 1990)
} 
repudiados por los lugareños que veían en ellos tanto el poder de enderezar las cosas como el de torcerlas con voluntad maligna. Los brujos o tlatlacatecolo eran personajes muy temidos entre la gente común.

Las prostitutas aparecen ocasionalmente integradas al orden, ya sea como cortesanas oficiales al servicio de los bravos guerreros de élite, ya como parte indispensable del ritual. Pero también existía una prostitución espontánea, naturalmente difícil de controlar, cuya contratación tenía lugar en las esquinas de las calles. Las mujeres que se ganaban la vida de esta forma, probablemente desprovistas de lazos familiares, o muy miserables, eran repudiadas y vistas con gran desprecio. Otras mujeres las insultaban y la gente las acorralaba en la calle para presenciar su agravio.

Quizá cualquiera podía excederse en la bebida ocasionalmente: dentro de la casa, lejos de la mirada vigilante de la policía. Pero había quienes sistemáticamente se entregaban a beber. Dicen los informantes nahuas, hablando de estos borrachos habituales, que con su conducta hacían que el viento arremolinado pasara por su casa destruyéndolo todo. Estos borrachos se confunden en la fuente con vagabundos y miserables: pernoctan en la calle, están andrajosos, sucios y llenos de inmundicia; carecen de escrúpulos, retan a la gente, gritan amenazantes. También ellos, como las prostitutas, solían padecer el acoso y escarnio públicos.

Los ladrones, en fin, aparecen también una y otra vez. Los hay que roban casas, como los temacpalitotique de que habló López Austin, 8 y los hay que asaltan en los caminos. Los caminantes tenían gran temor de ellos y existían conjuros especiales para repelerlos. Los más afamados actuaban en equipo y se disfrazaban con la piel del jaguar: del jaguar tomaban la fuerza.

\section{El pueblo llano}

He mencionado a dos grupos con gran movilidad -mercaderes y marginados-que seguramente son importantes en la configuración social del Valle de México pero que no dejan de ser minoritarios "Ahora quisiera referirme propiamente al pueblo llano, a los hombres de las comunidades de productores. Tres aspectos he encontrado hasta el momento en los cuales puede apreciarse una oposición entre pueblo y élite, y por lo tanto una modalidad específicamente popular de vivir la cultura; me refiero al lenguaje, a la religiosidad y al orden moral.

${ }^{8}$ Alfredo López Austin, "Los temacpalitotique", Estudios de Cultura Náhuatl, vol. VI (México, 1966) 


\section{1) Lenguaje}

Me causó gran sorpresa cuando conocí una frase hecha de las que componen el capítulo 43 del libro VI del Códice Florentino que dice tecuic, tetlatol. Con ella se arroja un llamado de atención al macehual que quiere adornarse hablando como noble, y se establece una clara oposición entre macehuallatolli y pillatolli. ${ }^{9}$ También en el lenguaje corporal se reproduce esta diferencia: el cuerpo del noble, erguido, está ricamente adornado con orejeras y bezotes, con plumas y brazaletes, envuelto en algodón bordado; el cuerpo del macehual, humillado por la costumbre de la reverencia, apenas está cubierto por una ligera y áspera capa de henequén.

Macehual y noble caminan en forma distinta y se sientan también en forma distinta. ${ }^{10}$ Sobre las diferencias en su hablar, los materiales de Sahagún brindan la mejor muestra. Y aquí vale la pena recordar la reflexión del fraile cuando está aclarando que no contó para su obra con literatura escrita, a la manera de los autores latinos que usó Calepino. Dice allí que "se han escrito doce libros de lenguaje propio y natural de esta lengua mexicana, donde allende de ser muy gustosa y provechosa escritura, hallarse han también en ella todas maneras de hablar, y todos los vocablos que esta gente usa..."

$\mathrm{Y}$ en efecto, aunque predominen en sus papeles las muestras del habla digamos culta, refinada pero estereotipada también $-y$ en ese sentido pobre-de la nobleza, Sahagún alcanzó a tomar muestras de hablas propias de algunos oficios y propias del pueblo. Las listas de vicios de los Primeros Memoriales contienen vestigios del habla popular, al igual que el material sobre supersticiones. Pero la mejor muestra parecen ser los folios sobre reñimientos y saludos de los mismos Primeros Memoriales. Aquí los informantes precisan antes de cada texto si se trata de las palabras usadas por los pipiltin o de las usadas por los macehualtin. Cuando traduje este material presenté algunas notas sobre sus implicaciones sociológicas; una de las cosas que llamaban mi atención era que los nobles evitaran el uso de insultos. Ésa era una de las diferencias más notab̆les: Ios macehuales no

\footnotetext{
${ }^{9}$ Lo referente al lenguaje hablado lo he discutido en Pablo Escalante, "Cortesía y vituperio entre los antiguos nahuas", La Gaceta del Fondo de Cultura Económica, núm. 224, México, Fondo de Cultura Económica, agosto de 1989; "Insultos y saludos...", op. cit.

${ }^{10}$ Realmente la totalidad de la conducta corporal está modificada por la situación social del actor. Estas ideas son discutidas en Pablo Escalante: "El cuerpo y el gesto. La conducta corporal entre los antiguos nahuas", documento de trabajo para el Seminario de Pictografías Mesoamericanas de los Institutos de Investigaciones Estéticas e Investigaciones Históricas de la Universidad Nacional Autónoma de México.

${ }^{11}$ Sahagún, op. cit, , p. 21 .
} 
tenían mayor escrúpulo en defender su territorio barrial insultando a gritos a los intrusos de oscuras intenciones.

Si tomamos en cuenta la importancia que tenía en el calmécac y en palacio la enseñanza de la retórica, y el énfasis que se ponía en las maneras correctas del noble, corporales o verbales, resulta claro que había un esfuerzo consciente por acenturar las diferencias y construir un lenguaje exclusivo de la nobleza.

\section{2) Religiosidad}

Postular la existencia de una religiosidad popular para la época prehispánica puede parecer descabellado. Pienso por ejemplo que los estudiosos del sincretismo religioso, y en general de la religión colonial novohispana, hablan de una religiosidad popular colonial que, suponen, deriva de las antiguas religiones indígenas, pero niegan tácitamente la existencia de ambas modalidades religiosas, popular y oficial, en la época prehispánica. Pienso que esta postura se encuentra tan generalizada como poco fundada: se supone que el pasado prehispánico era ajeno a la contradicción popular-culto o popular-dominante.

En los manuscritos de Sahagún se habla mucho de religión; es lógico porque era su preocupación fundamental. Y se habla sobre todo de la religión oficial: las grandes fiestas centrales, el templo mayor y los sacerdotes del culto oficial y sus oraciones. Sin embargo, creo que también hay indicios de una religiosidad popular; algunos de ellos ya han sido presentados en las discusiones sobre el calpulli. Se ha dicho con razón que cada barrio tenía su propia organización religiosa. Cada barrio o conjunto de barrios rendía culto a un dios tutelar determinado; para dicho culto había un templo del barrio y un ceremonial propio. Las fiestas religiosas del barrio tenían sus fechas. Los calpullis participaban en las fiestas oficiales pero no dejaban de practicar un culto local. ${ }^{12}$

Esta cierta autonomía del calpulli en los quehaceres religiosos quizá no sería razón suficiente para hablar de una religiosidad popular, pero existen indicios de una manera popular de vivir la religión, en donde vemos diferencias de concepción en relación con la religión de la nobleza o

\footnotetext{
${ }^{12}$ Quien me llamó la atención por primera vez sobre la existencia de un culto de calpulli y un culto del tlatocáyotl fue Alfredo López Austin. Incluyen en su definición del calpulli la consideración de la autonomía religiosa Víctor Castillo, op cit, y Alfredo López Austin, "Organización política en el Altiplano Central de México durante el Posclásico", Historia Mexicana, vol. XXIII, México, El Colegio de México, abril-junio de 1974
} 
religión oficial del tlatocáyotl. Una diferencia importante, pienso, está en la concepción de los espacios sagrados. La religión oficial delimita un área, v.gr. el recinto del Templo Mayor, y procura convertir dicha área en el espacio sagrado por excelencia en oposición a su entorno profano. Sólo en determinadas fechas el calendario de la religión oficial indica el culto en espacios abiertos como los montes de la cuenca o el sumidero de la laguna. En contraste, la mentalidad popular acepta que el mundo todo está habitado por fuerzas sobrenaturales (idea que prevalece solamente en forma residual entre la nobleza). Así, el hombre común mira el río, el bosque, la montaña, la cueva, el camino mismo, como ámbitos sagrados, aunque haya momentos particularmente propicios para el ritual. ${ }^{13}$ Esta concepción tiene consecuencias importantes sobre la visión del sacerdocio: para la religión oficial el sacerdote es un mediador indispensable entre el pueblo y los dioses; lo dejan sobradamente claro las oraciones de los sacerdotes principales a Tezcatlipoca ${ }^{14}$ Para la gente común hay un nivel intenso y cotidiano de comunicación directa con lo sobrenatural, sin mediación. El sacerdote sería en todo caso un humilde encargado de ofrendar continuamente, de servir por oficio a los dioses. La visión de la nobleza entraña, por supuesto, el desarrollo de una intención política.

Aún más en el fondo, la concepción que tiene de los dioses la religión nobiliaria es estrictamente señorial. Los dioses de los primeros libros del Códice Florentino son señores, ${ }^{15}$ y su función sobre cada mes es una función de mando equiparable a la que tenían los jefes políticos sobre sus súbditos. La visión popular de los dioses pudo haber sido bastante diferente.

A la luz de los relatos míticos populares conservados por la tradición oral durante siglos, se ha pensado que en la antigua concepción mesoamericana del cosmos y sus fuerzas los dioses no son diferentes de los elementos mismos de la naturaleza: están en ella, la habitan y su forma más personal, digamos, la adquieren en el cuerpo de los animales. Recientemente, al presentar López Austin pruebas a favor de la idea de que Quetzalcóatl puede ser el primitivo tlacuache, ${ }^{16}$ la idea se mostró aún más viable. El

\footnotetext{
${ }^{13}$ Los augurios y abusiones traducidos por López Austin pueden ser el mejor material para comprender esta relación con lo sagrado Alfredo López Austin, Augurios y abrusiones, México, Universidad Nacional Autónoma de México, 1969. Fuera de la obra de Sahagún, el material más valioso está en Jacinto de la Serna et al: Tratado de las idolatrías, supersticiones, ritos..., 2 vols México, Ediciones Fuente Cultural, 1953

${ }^{14}$ De hecho el sacerdote interpela a la divinidad diciéndole que le pide ayuda para los pobres macehuales. Estas oraciones comienzan el libto VI del Códice Florentino.

${ }^{15}$ Es muy importante estudiar ese proceso de atribución de rasgos del comportamiento, postura y atuendo de la nobleza a los dioses.

${ }^{16}$ Alfredo López Austin, Los mitos del tlacuache, México, Alianza Editorial Mexicana, 1990.
} 
caminante que se encontraba con un coyote lo miraba con atención porque podía tratarse de Tezcatlipoca, según los informantes de Sahagún.

También era Tezcatlipoca el Hacha nocturna, aquel degollado con el pecho abierto. $Y$ en este caso nos hallamos frente a la mentalidad popular como interpretación supersticiosa del ritual público del tlatocáyotl. El solemne y sangriento sacrificio de prisioneros de guerra, cuyos datos más dramáticos eran la rasgadura del pecho y el degollamiento, produce en la creencia popular un fantasma lastimoso que corre por los bosques exhibiendo sus carencias y haciendo burla o luchando con los caminantes nocturnos. ${ }^{17}$

\section{3) Moralidad}

Para terminar quiero referirme someramente al tema de la moralidad. ${ }^{18}$ En términos generales puedo decir que en la antigua sociedad nahua identifico, gracias a los textos sahaguntinos, una moralidad propia de la nobleza (reforzada por el orden público y la legislación) y una moralidad propia de las comunidades de macehuales. El principio rector del sistema moral de la nobleza es vertical y se cifra en virtudes como la obediencia y la sumisión. El principio que rige el sistema moral del pueblo es horizontal y depende de la virtud de la solidaridad.

La diferencia obedece, a fin de cuentas, al tipo de organización social que imperaba en México y otros tlatocáyotl en el Posclásico tardío. Sus consecuencias políticas son evidentes. Sin poder ahondar más por el momento en este planteamiento general, sí puedo referirme a un aspecto de él para brindar algún ejemplo.

Si consideramos a los huehuetlatolli que se recogieron para Sahagún como testimonios de la educación moral entre los nahuas y no ponemos atención en el problema de su carácter de clase llegaríamos a conclusiones equivocadas. Con el apoyo de algunos otros pasajes podría afirmarse que para los nahuas el recato premarital y la virginidad eran muy importantes, y que las licencias antes del matrimonio y el adulterio estaban muy severamente castigados, muchas veces con la pena de muerte. Sin ser falsa, esta

${ }^{17}$ La versión más completa de la historia del Hacha nocturna está en Alfredo López Austin, "El hacha nocturna", Estudios de Cultura Náhuatl, vol IV, México, Universidad Nacional Autónoma de México, 1963.

${ }^{18} \mathrm{La}$ exposición que he hecho de este tema ha sido solamente preliminar en Pablo Escalante: "Calpulli: ética y parentesco", ponencia presentada en el Coloquio de Historia de la Familia en México, Centro de Estudios Históricos, El Colegio de México, 30-31 de octubre de 1989 
visión es parcial. Sabemos que la ley no siempre se podía aplicar en materia de adulterio y que se aceptaban como cosa ordinaria los matrimonios entre jóvenes que habían vivido previamente amancebados. Esto ocurría entre la gente del pueblo donde la norma parece haber sido la tolerancia y la aceptación de las inclinaciones espontáneas, poniendo a éstas un límite sólo para preservar el orden comunitario.

Con riqueza, e incluso con gracia, los informantes indígenas de Sahagún nos permiten saber que el ámbito de cierto esparcimiento vespertino que representaba el cuicacalli era aprovechado por los jóvenes para cortejarse. A pesar de la vigilancia oficial, o quizá gracias a su complicidad, muchachos y muchachas se guiñaban el ojo para acordar una cita. Y era por eso que los jóvenes del telpochcalli no siempre dormían en el recinto con los otros; iban a dormir a la casa familiar de alguna amiga. Dicen los informantes, literalmente, que los jóvenes del telpochcalli "tenían sus amantes, de a dos, de a tres; quizá una está en la casa, quizá las otras están dispersas", ${ }^{19}$

No quiero extender me más en estas notas. Una conclusión imprescindible sería reiterar el gran valor historiográfico y la riqueza sin par de la obra de Bernardino de Sahagún y sus informantes: Antonio Valeriano, Alonso Vegerano, Martín Jacobita, Pedro de San Buenaventura y otros varios hombres y mujeres comunes, memoriosos, viejos y sabios. El corpus debido a ellos, a pesar de limitaciones como las apuntadas por Calnek, es la mejor ventana que tenemos para asomarnos a la vida en México antes de la conquista española.

${ }^{19}$ Alfredo López Austin, Educación mexica Antologia de textos sahaguntinos, México, Universidad Nacional Autónoma de México, 1985, p. 37. 